\title{
Branje kot prostorska praksa: odnos bralcev do neposrednega fizičnega prostora branja
}

Ključne besede: bralno doživetje, bralno okolje, telesnost branja, poglobljeni intervju

DOI: $10.4312 /$ ars.13.2.163-183

\section{Uvod}

»Vsako branje je 'prizemljeno' - vedno se zgodi v telesu, ki je vselej nekam locirano« (Mackey, 2016, VIII; prev. A. Č. V.). ${ }^{1}$

Pričujoči članek skuša na podlagi poglobljenih individualnih pogovorov z bralci o njihovih bralnih navadah izluščiti, kako realni prostor branja sooblikuje bralno izkušnjo. Osredotoča se na branje leposlovja za prosti čas in na branje domá, kar so sogovorniki sami postavili v središče, obravnava branje na prostem in v javnosti, dotika pa se tudi vprašanja, kako prostor branja spreminja digitalizacija. Pri tem vseskozi izhaja iz teoretske perspektive utelešene kognicije ter branje razume kot izrazito telesno in materialno prakso.

\section{Opredelitev in umestitev tematike}

Čeprav tiho, individualno branje, ki nam je danes vsem samoumevno, korenini v glasnem (in pogosto javnem) bralnem aktu - to je bilo zaradi pomena afekta v antiki pogosto teatralično, zaradi drže svitkov pa tudi fizično zahtevno -, se je dojemanje branja vsaj do konca 18. stoletja povsem omejilo na njegovo mentalno, razumsko, kognitivno, skratka netelesno dimenzijo. Kompleksno bralno dejanje je tako postalo in ostalo del literarnih ved, vse dokler niso intervencije drugih disciplin približno od osemdesetih let prejšnjega stoletja naprej ponudile novih uvidov in heterogenizirale pristope raziskovanja branja ter kot predmet preučevanja nazadnje uveljavile tudi konkretnega bralca iz mesa in kosti. ${ }^{2}$

1 "All reading is 'earthed' - reading always happens with a body that is always located somewhere."

2 K temu so pomembno prispevali novi historizem, postkolonialne študije in študije spolov, pa tudi zgodovina branja ter pristopi medijskih in kulturnih študijev, antropologije, psihologije in nazadnje nevroznanosti. Dober pregled teorij branja z vidika (ne)obravnave zunajtekstualnega, empiričnega bralca ponuja K. Littau v Theories of Reading. Books, Bodies and Bibliomania (2006). 
Literarna veda realnega bralca najbolj neposredno naslavlja v okviru t. i. empiričnih literarnih študij, ki pa se v veliki meri odmikajo od njenih tradicionalnih postavk. Gre za izjemno raznoliko področje, ki se (vsaj z imenom) poveže v osemdesetih letih prejšnjega stoletja in ga - poenostavljeno rečeno - druži na eni strani literatura, na drugi pa empirične metode raziskovanja njene produkcije, distribucije, recepcije in besedil samih. Ker empirija izhaja iz izkustva, logično temelji na čutnem dojemanju in v tej luči empirične literarne študije obravnavajo tudi bralno doživetje. Od konca prejšnjega tisočletja branje intenzivno raziskujemo $\mathrm{v}$ luči paradigme utelešene kognicije, ${ }^{3}$ ki poudarja senzomotorično osnovo kognitivnih aktivnosti. K temu sta po svoje prispevala tudi t. i. prostorski in afektivni obrat v literarni vedi (in širše v humanistiki). Ob vsem povedanem se zdi vloga oziroma doživljanje prostora kot ambientalne mikrolokacije pri branju razmeroma relevantna tema.

A študij, ki bi preučevale pomen okolja na bralno izkušnjo, kljub temu ni veliko. Opozorilo staroste zgodovine knjige in branja Rogerja Chartierja iz leta 1992, da je branje "praksa, ki se zmeraj uteleša v gestah, prostorih in navadah«, saj ni zgolj "abstraktni proces intelekta, pač pa v igro pritegne tudi telo, pomeni vpis v prostor, odnos do sebe in do drugih « $(2011,6,13)$, sicer ima svoj učinek, a tema večinoma ostane vezana na zgodovinske preglede oziroma posamezna historična obdobja (gl. Flint, 1993; Raven idr., 1996; Manguel, 1997; Fischer, 2004; Colclough, 2007, 2011; Williams, 2015).

Analiz, ki bi vzele pod drobnogled prostorski kontekst sodobnega bralca, je bistveno manj - in še te se praviloma ukvarjajo $\mathrm{z}$ vlogo okolja pri razvoju literarnih kompetenc (gl. Burgess idr., 2002; Lesseman idr., 1998). A nekaj je vendarle tudi takih, ki neposredno zadevajo vpliv fizičnega konteksta na bralno doživetje. Študije Literary Reading, Cognition and Emotion Michaela Burka (2011), Reading and the Body Thomasa McLaughlina (2015) in Does it Matter Where You Read? Anežke Kuzmičove (2016) bralni proces obravnavajo (tudi) z vidika prostorske umeščenosti. Vendar pa njihova analiza ne izhaja iz izkušenj dejanskih bralcev - mene pa so zanimale prav te.

\section{Metodološki okvir}

Tukajšnji prispevek o vlogi prostora razmišlja na osnovi poglobljenih pogovorov z bralci in bralkami o njihovih lastnih bralnih izkušnjah. Gre za kvalitativno analizo polstrukturiranih intervjujev. Posebej me je zanimalo, kako - in če sploh - se bodo v

3 Po teoriji utelešene kognicije je vsako razumevanje zasidrano v telesnem, v naravi in sestavi človeških teles, ter v načinu interakcije s svetom okoli nas, ki je vsaj toliko kulturni kot biološki proces (Wilson, 2002). Na osnovi vse številčnejših raziskav, ki to potrjujejo, se v zadnjih desetletjih vse bolj uveljavlja ta, t. i. nekartezijanski pristop kognitivne znanosti (Rowlands, 2010; Sadoski, 2018). 
opisu svojega bralnega vedenja navezali na prostor in kako bodo sami ubesedili pomen prostora. $\mathrm{V}$ ospredju sta torej odnos do prostora ter bralčeva percepcija njegovega vpliva in ne neposreden vpliv prostora na branje, kar bi morali »meriti« $\mathrm{z}$ drugačnimi metodološkimi pristopi.

$\mathrm{V}$ ta namen sem od aprila lani (začeli smo prav na Noč knjige, 23. 4. 2018) v Vodnikovi domačiji - hiši branja, pisanja in pripovedovanja - izpeljala 17 pogovorov s posamezniki, ki so se odzvali mojemu vabilu na "pogovor o branju«. To je bilo praviloma tedensko objavljeno v programskem novičniku Vodnikove domačije in na Facebooku ter poslano na listo prejemnikov. ${ }^{4}$

Pogovore sem vodila približno enkrat ali dvakrat na mesec, izmenjaje $\mathrm{v}$ dopoldanskem in popoldanskem terminu. Potekali so na samem, v t. i. sobi za pisanje, ob čaju in piškotih. Trajali so eno do dve uri, največkrat približno uro in četrt. Vsi so bili posneti na diktafon in transkribirani, podatki pa anonimizirani. Sogovorniki so v zapisu označeni s kratico za spol in zaporednim številom (na primer M7).

Po kratki uvodni predstavitvi samega pogovora in namena raziskave sem najprej vsakega sogovornika prosila, naj opiše, kakšne vrste bralec je in kako bere. Tako sem lahko opazovala, kaj izpostavi oziroma na kaj najprej pomisli, in ga šele potem vodila skozi nabor tem oziroma vprašanj. ${ }^{5}$ Za tematiko prispevka so bila ključna predvsem sledeča: kako berete? Kdaj in kje najpogosteje berete? Kako okolje vpliva na to, kaj in kako berete? V kakšnih okoliščinah najrajši berete? Nanje sem navezala vrsto podvprašanj, med drugim: ali berete zunaj, na prostem? Ali kdaj berete v javnosti? Kje vse berete doma? Berete sami in $\mathrm{v}$ tišini ali imate radi zvoke v ozadju in koga v bližini? Ali se spomnite, kje ste brali določeno knjigo?

A brez ostalih vprašanj, ki širše zadevajo bralne navade posameznika, bi si težko oblikovala ustrezno predstavo o vlogi prostora pri branju, saj so se sodelujoči na to pogosto spontano navezali pri drugih odgovorih, kar je še posebej pomenljivo. Vrstni red vprašanj sem vsakokrat sproti prilagajala toku pogovora, včasih sem glede na ponujeno iztočnico - kakšno vprašanje dodala, včasih pa tudi izpustila. Nekatera sem namenoma zastavila večkrat, a v parafrazah in $\mathrm{z}$ različnimi poudarki, ter si s tem poskusila zagotoviti čim bolj izčrpno obravnavo tematike. Včasih sva se s sogovornikom pri kakšni temi »zataknila« in jo dodatno razčlenila. Ob tem sem

4 Vabilo je aktualno, saj projekt še traja. Zadnji intervju, ki je vključen v obravnavo, je bil opravljen aprila 2019. Na tem mestu bi se rada vodstvu in ekipi Vodnikove domačije toplo zahvalila za vso dosedanjo podporo in gostoljubje.

5 Odnos do prostora je bil sicer le eden izmed opazovanih parametrov. V osnovi sem želela v poglobljenih individualnih intervjujih s prostovoljnimi sogovorniki podrobno razpravljati o tem, kako berejo, in to $\mathrm{z}$ vsemi morebitnimi kapricami vred. Vendar so bili fizično-materialni vidiki branja vedno v ospredju mojega zanimanja, kar je bilo jasno razvidno tudi iz vabila k sodelovanju. 
se kot spraševalka učila tudi sama in tako sproti modificirala oziroma dopolnjevala nabor debatnih točk.

Poudarek je bil vseskozi na bralnem vedênju in ne na literaturi. Oboje se seveda prepleta, a hierarhija pomena je bila jasna. S tem sem se, mislim, vsaj deloma izognila vrednotenjskim implikacijam, ki jih močneje občutimo pri govorjenju o tem, kaj beremo, kot pri opisovanju osebnih bralnih navad. Po pogovoru sem sodelujoče prosila še za podatke o starosti, izobrazbi in poklicu.

\section{Sodelujoči}

Nabor 17 sogovornikov, starih med 25 in 72 let, sicer ni demografsko reprezentativen, gotovo pa realno odraža profil ljudi, ki berejo in se želijo o tem tudi pogovarjati. V tej luči ni presenetljivo, da so se na moje vabilo odzvale predvsem (starejše) ženske - od 17 sodelujočih je bilo kar 13 žensk, od tega 8 starih 50 let in več.

Kljub pričakovanju me je intenzivnost tega vzorca, ki je bil najočitnejši na začetku, presenetila. Prvih šest gostov je bilo žensk; od tega tri upokojenke in dve (trenutno) brezposelni. Šele kasneje, ko se je o bralnih intervjujih razvedelo nekoliko širše, se je popestril tudi nabor sogovornikov, a najprej so očitno nagovorili prav to skupino. Eden od razlogov gotovo tiči v njihovi večji časovni razpoložljivosti, poleg tega je znano, da - tudi pri nas - bere več žensk kot moških (gl. Kovač idr., 2015). Zdi pa se, da je bilo med ženskami tudi več takih, ki so se bile o branju pripravljene ali celo željne pogovarjati.

Zgovoren je podatek, da so vsi moški sogovorniki predstavniki izrazito beročih poklicev (prevajalec, urednik, profesor), medtem ko so med ženskami take (le) štiri. Očitno so se ženske prej čutile nagovorjene zgolj kot bralke, kar je bil tudi moj namen - nikakor nisem želela ustvariti vtisa, da me zanimajo samo profesionalni bralci.

Vsi razen ene imajo visoko izobrazbo, devet pa še magisterij ali doktorat, med njimi so tudi vsi sodelujoči moški. Prevladujejo družboslovci, dve prihajata s področja oblikovanja.

\section{Pogovori o branju: izsledki in razprava}

Čepravnisem tegazvprašanjizničemer predpostavila, jevelikavečina sogovornikov, ki so se vsi identificirali kot ljubitelji branja, na moja vprašanja odgovarjala $\mathrm{z}$ mislijo na prostočasno branje. Razen nekaj tistih, ki jim je branje poklic, so idejo branja najprej povezali s sprostitvijo in užitkom. Podobno večinsko (12 proti 5) so branje primarno identificirali s tiskanimi besedili. Šele na mojo izrecno poizvedbo so se razgovorili tudi 
o t. i. študijskem in drugih oblikah branja oziroma o branju na digitalnih nosilcih. Prav tako jih je največ povedalo, da berejo doma, v postelji ali na kavču, popoldne oziroma zvečer. V preseku je bila tako njihova najpogostejša asociacija na branje tradicionalna podoba bralca $\mathrm{z}$ romanom $\mathrm{v}$ roki, udobno zleknjenega nekje doma.

Toda ta vtis je vsaj deloma zavajajoč. Eksplicitni odgovori sodelujočih se niso vedno ujemali z njihovimi implicitnimi sporočili. Zato je bilo zame v resnici zelo poučno spremljati, kako so sogovorniki pomen prostora artikulirali posredno, največkrat prek opisov svojih telesnih občutenj pri branju oziroma v odnosu tako do vsebine knjige kot do njene predmetnosti. Kot se je izrazila ena od sodelujočih: "Branje je zame posebno razpoloženje« (Ž10). In to razpoloženje pomembno sodoločajo neposredne fizične okoliščine. V tem smislu sta telo in prostor neposredno povezana in skupaj s prebranim tvorita občutenje, ki podlaga kognitivno dimenzijo bralne izkušnje.

Poglavje je razdeljeno na štiri segmente: prva dva - »branje doma« in »branje na prostem oziroma v javnosti« - označujeta dva osrednja tipa bralne lokacije, tretji, "prostor (za) knjige«, se nanaša na prostorsko doživljanje knjig pri branju in na fizično sobivanje z njimi, zadnji, »branje kot kompleksna senzorična in prostorska izkušnja «, pa povedano poveže skozi perspektivo telesnosti in afektivnosti bralne izkušnje.

\section{Branje doma}

$\mathrm{V}$ tem segmentu se osredotočam na branje doma ter na vse tisto, kar so v tej zvezi povedali sodelujoči in v prepletu zadeva časovno-prostorske koordinate (kje in kdaj doma berem), tip branja (kaj berem doma oziroma s kakšnim namenom, kar se največkrat nanaša na izbiro bralnih naprav) in naravo te izkušnje (občutja, učinki).

Prostočasno branje

»Največkrat berem na postelji ali kavču« (Ž6).

»Po navadi berem leže» (M9).

Intervjuvanci so imeli na pričakovano vprašanje, kje oziroma kako berejo, zelo pogosto "pripravljen « odgovor, v katerem so opisali svojo predstavo o lastnem branju: 15 od 17 jih je reklo, da berejo (napol) leže v spalnici ali dnevni sobi. A praviloma se je izkazalo, da tako berejo samo takrat, kadar se odločijo za dolgotrajnejše druženje s knjigo za lasten užitek, ki je pogosto načrtovano ali celo v funkciji nagrade.

»Branje je moja nagrada, crkljanje same sebe« (Ž12).

»Ko vse uredim, se usedem k branju; to je moje zlato« (吕2). 
Skoraj vsi so rekli, da berejo pred spanjem, le da je to za nekatere obvezen ritual, za druge pa zgolj pogosta navada.

»Branje pred spanjem, vsaj 15 minut, je vsakodnevna stvar« (M15).

"Ne vem, ali se mi je v življenju dvajsetkrat zgodilo, da nisem brala pred spanjem» (亡̌2).

Branje pred spanjem je pogosto povezano s točno določeno literaturo, ki pomirja oziroma deluje blagodejno.

»Pred spanjem kdaj preberem samo kakšnega Rumija, kak njegov verz, da se malo ustavim in umirim $«(\check{Z} 3)$.

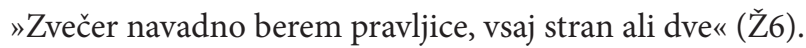

\section{Študijsko branje}

Službeno ali študijsko branje in branje novic oziroma periodike predpostavlja drugačno »scenografijo«. Četudi lahko v seštevku časovno zajemajo večji delež, so ta branja - vsaj po pričevanju sogovornikov - neredko percipirana kot "ne-čisto-pravo branje«, kar pa ne velja za nekaj tistih, ki berejo profesionalno. T. i. delovno branje največkrat vključuje branju dodane protokole - podčrtovanje, izpisovanje, ponovno branje - in predpostavlja manjšo stopnjo udobja, tj. vsaj vzravnano sedenje za mizo in pogosto tudi delo za računalnikom, kar ga po navadi locira v delovni prostor, ki ni niti spalnica niti dnevna soba.

»Ko sem študirala, sem brala za mizo in si delala izpiske [...] To še vedno počnem, če moram napisati kak članek« (Ž4).

»Študijsko literaturo vedno berem na laptopu, zraven si priklopim ekran in si delam zapiske« (Ž13).

Kot ugotavlja McLaughlin, vzravnana drža za delovno mizo še ne zagotovi niti discipliniranega niti uspešnega branja, a kljub temu vzpostavi odnos do dela, "pripravi telo« $(2015,72)$. Študijsko branje je namreč vedno več kot »le« branje, je nekakšna priprava na kasnejšo demonstracijo znanja in s tem faza $\mathrm{v}$ daljšem, kompleksnejšem procesu.

\section{Papir vs. zaslon}

Vsi razen štirih sogovornikov mlajše generacije prostočasno berejo izključno $\mathrm{v}$ tisku. Branje na pametnem telefonu, digitalnem bralniku ali tablici povezujejo $z$ informativnim branjem novic in pregledovanjem socialnih omrežij, branje na (prenosnem) računalniku pa - ob vsem naštetem - tudi oziroma predvsem $\mathrm{z}$ delom. 
»Te naprave povezujem z resnimi, službenimi zadevami« (Ž17).

Tudi zato komentarji v stilu: »Kar berem po spletu, zame ni branje« (Ž13); »Branje na računalniku ni ravno branje« $(\check{Z} 11)$ - niso bili redki.

Delitev branja na profesionalno in zasebno je bistveno bolj zabrisana pri tistih, ki jim je branje tako rekoč glavna poklicna preokupacija.

»Težko branja ne jemljem kot delo; ne nazadnje sem diplomiral in doktoriral iz literature, je pa seveda razlika, ali je to delo zoprno ali fajn« (M14).

»Moji načini branja si postajajo podobni oziroma se povezujejo - večinoma lahko uživam v branju, ki je sociološko, in obratno; literaturo vidim kot material za sociologa $«(M 7)$.

A tudi ti »poklicni« bralci ločujejo med branjem, ki zahteva denimo korigiranje, delo $\mathrm{z}$ računalnikom in sedenje za mizo, ter manj omejujočim branjem, pa tudi med prostovoljnim in zahtevanim študijem.

"Za mizo berem izključno sprintane akademske članke, zato ker je bolj nerodno, če prelagaš liste po postelji« (M14).

»Na računalniku berem samo, kadar prevajam in ko delam research za članke» (M15).

\section{Specifika domačega branja}

Zelo pogosto se branje vpleta med vsakdanja domača opravila: sogovorniki so poročali, kako berejo med jedjo, ob jutranji kavi, na stranišču ali v kadi, in sicer tako knjige kot kaj krajšega na pametnem telefonu. Aktualno čtivo se tako pomika $\mathrm{z}$ njimi po hiši.

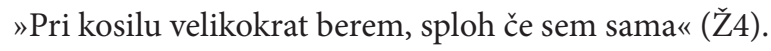

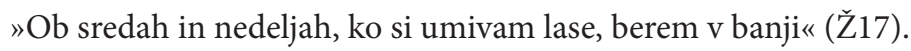

Dom v izjavah bralcev, s katerimi sem govorila, nastopa kot prostor udobja in sprostitve, odvezan od zunanjih omejitev, in kot okolje, ki si ga lahko »ukrojimo po svoji meri«. V njem imamo stvari v glavnem pod nadzorom in si lahko ustvarimo ustrezne razmere za branje. Bralci lahko tako svojim trenutnim potrebam prilagajajo sam prostor branja, držo telesa, svetlobo in oblačila; kreirajo lahko lastno zvočno ozadje, ${ }^{6}$ menjajo čtivo, si skuhajo kavo, skratka, lahko sledijo svojim »kapricam«.

6 O zvočnem okolju branja so se sogovorniki precej razgovorili, vendar tema presega vsebinske okvire tega članka. 
»Ko berem, si dam hlače po navadi dol in se pokrijem. Rad sem v pižami ali v dolgih spodnjih hlačah. [...] Če si doma, greš lahko na WC ali kaj spit, lahko imaš noge gor - drugje pa nisi gospodar situacije« (M14).

»Rada imam veliko svetlobe ali dobro luč, zraven moram imeti vodo in na koščke si narežem surovo sadje ali zelenjavo ...« (Ž16).

Domače razmere ustvarjajo občutek varnosti. Čeprav so nekateri udeleženci omenjali tudi balkon oziroma vrt ali teraso in menili, da brez težav berejo tudi ob prisotnosti drugih, je bilo očitno, da doma večinoma berejo v notranjih prostorih, in to sami. ${ }^{7}$

Če pa dom ne ponuja osnovnega udobja, izgubi tudi funkcijo primarnega bralnega okolja, kar lepo pokaže primer bralke, ki - kot pravi - doma ne more brati in zato redno uhaja v knjižnico.

»V stanovanju, v katerem zdaj živimo, se ne počutim dobro, ker je nefunkcionalno, in tam ne morem zares brati. Imamo kavč, ampak tam je tudi televizija in tam se jé [...] Zato hodim brat v knjižnico. Tam imam mizo in svoj prostor in se lažje fokusiram« (亡̌3).

A kot pokaže nadaljevanje, o branju na prostem in $\mathrm{v}$ javnosti poročajo tudi vsi ostali sogovorniki.

\section{Branje na prostem, branje $v$ javnosti}

Udeleženci raziskave so med kraji, kjer berejo zunaj dóma, največkrat navedli plažo, park, javna prevozna sredstva - predvsem vlak - ter kavarne. Razen v enem primeru knjižnice nastopajo predvsem kot kraj izposoje oziroma kot del spomina na učenje v čitalnicah.

»Poleg dóma rada berem še ob morju in na vlaku, pa tudi v parku, živžav me ne $\operatorname{moti} \ll(\check{Z} 2)$.

»Med študijem sem hodila v tiste res tihe čitalnice, kakršna je NUK. ... [Danes] knjigo vzamem s sabo v kavarno, berem na vlaku, na morju na plaži ali v mreži« (亡̌12).

A za večino je mogoče razbrati, da zunaj praviloma berejo zgolj priložnostno ali po spletu okoliščin - bodisi pridejo kam prezgodaj in morajo (po)čakati, bodisi tako

7 Raziskava bralnih navad, ki smo jo izvedli leta 2017 (gl. Kuzmičová idr., 2017), kot eno zanimivejših sicer izpostavlja ravno ugotovitev, da prisotnost drugih med branjem številnim ni le nemoteča, pač pa prijetna in zaželena. Tega tu nisem opazila, res pa je, da je šlo takrat za študijo fokusnih skupin študentov, ki so večkrat poudarili izrazito pozitiven učinek čitalniške atmosfere - tudi zato, ker je lahko domače udobje zlasti pri študijskem branju včasih kontraproduktivno. 
zapolnijo »časovno luknjo«, ali pa jih prijetno vreme in prosta klopca zvabita v branje na poti domov. Bolj kot za kaj drugega gre skratka za to, da izkoristijo vmesni čas.

»Knjigo imam sicer s sabo, ampak ne berem ravno veliko zunaj, bolj iz želje, da bom bolj učinkovita, ne iz užitka« (Ž11).

»Med vožnjo rada berem, ker te tranzicije so izguba časa, in branje je potem nekakšen izkoristek, boljše se počutim« (Ž10).

$\mathrm{V}$ ta namen praviloma nosijo knjige s seboj, vendar se sami od sebe tja sicer ne bi namenili brat.

»Da bi šla namenoma brat v kavarno, to ne, ampak če sem že tam, potem pa ja« (亡̌16).

»Ko prihaja pomlad, si večkrat rečem, da bom šla brat v park, ampak se potem ne spravim ...«(Ž 12$)$.

Tistih, ki gredo načrtno brat ven, je manj, in ti so »zverzirani« zunanji bralci, ki javni ambient poiščejo $\mathrm{z}$ razlogom.

»Moja priljubljena točka za branje je Volčji potok. Tam je nekaj zelo dobrih klopc za branje in tja si včasih odnesem knjige in sem ves dan $\operatorname{tam} «(\check{Z} 5)$.

»Poleti grem rada v Tivoli ali pa ob kakšno reko, dam si deko pod drevo in berem. Res pa je, da bolj malo preberem, ker to potem ni samo branje, ampak doživljanje okolice« (Ž10).

Toda niso vse kombinacije okolja in čtiva uspešne: po izkušnjah intervjuvancev je res dobro knjigo mogoče brati tudi v razmeroma motečem okolju (na primer v glasni kavarni ali na nagnetenem vlaku), podobno velja za lahko branje, medtem ko je veliko težje vztrajati pri bodisi zahtevni bodisi slabi literaturi.

»V̌̌asih grem brat v kavarno pri Španskih borcih, kjer je res fajn prostor. Če knjiga ni prezahtevna, lahko berem tudi ob šundru in glasbi« $(\check{Z} 3)$.

»Berem tudi v kavarni ali če grem na kosilo, a s predpostavko, da imam s sabo tekst, ki ga lahko prekinem« (M7).

To se ujema z ugotovitvami A. Kuzmičove (2016), ki pravi, da smo pri branju zahtevnega leposlovja bolj občutljivi na okolico. Prvič zato, ker kompleksno besedilo zahteva več fokusne pozornosti in truda, zato smo pri takem branju bolj »ranljivi« in prej zaznamo motnje iz okolja. Drugič pa zato, ker zahtevna besedila z raznimi jezikovnimi tehnikami pogosto vzpostavljajo estetsko distanco, kar pomeni, da senzibilizirajo bralca za podrobnosti in ga odprejo za refleksijo, s tem pa naredijo 
dovzetnejšega tudi za okolje - in to tako v pozitivnem kot negativnem smislu. Če okolje dojemamo kot prijetno, to pri kompleksnem branju opazimo prej, in obratno, okolje, ki nam ni preveč všeč, nas bo pri takem branju bolj motilo. Kot je opazil eden od intervjuvancev: „Če berem v kavarni in nekdo pri sosednji mizi kvasi neumnosti, me bo to bolj motilo, kot če ne bi bral« (M7). Potreba po zadovoljujočem okolju naj bi tako naraščala s kompleksnostjo besedila.

\section{Branje na morju in branje na vlaku}

Poglavji zase sta branje na morju in branje na vlaku. Branje zunaj je že tako ali tako vremensko pogojeno in zato bolj sezonskega tipa, branje na morju pa še prav posebej. ${ }^{8}$ Ker je (običajno) vezano na dopust, konotira počitniško svobodo, časovno razkošje in razpuščenost, kar ga uvršča med najbolj priljubljene bralne situacije. Skoraj vsi naši sogovorniki so zatrdili, da poleti na dopustu veliko berejo: »Samo na morju lahko berem v kosu« (̌̌12); »Na dopustu berem več« (M14).

Večinoma sicer priznavajo, da največ preberejo v diskretnejšem morskem okolju, tj. v senci borovcev, na terasi ali celo palubi - in ne na plaži.

»Na morju nikoli ne berem na plaži, ampak na terasi v naslanjaču« (Ž16).

»Ogromno preberem v kampu ob šotoru« (M15).

Prav tako med omembami izstopa branje na vlaku. Vožnja z vlakom je tako rekoč utelesitev procesa, ki ga Green in Brock pomenljivo poimenujeta transportation - v dobesednem prevodu prenos, $\mathrm{v}$ pomenskem pa vživetje oziroma potopitev - in konceptualizirata kot »integracijo pozornosti, mentalne upodobitve prebranega in občutij« (2000, 703). Pri tem se navežeta na kognitivnega znanstvenika Richarda J. Gerriga, ki je v začetku devetdesetih uporabil dobesedno izkušnjo potovanja, da bi razložil procese, ki se pojavijo, ko se bralec poglobi v besedilo. Kombinacija mentalnega in fizičnega "prehajanja svetov« ob enakomernem ritmu in relativnem udobju vožnje omogoči posebno zamaknjenost, ki pogosto poglobi bralno doživetje. Skoraj polovica sogovornikov je branje na vlaku navedla kot eno prijetnejših bralnih izkušenj.

»Na vlaku berem odlično [...] Vlak je kot film: sediš in gledaš, kako svet teče mimo tebe in ustvarja eno tako distanco, idealno za branje. Zdi se mi, da na vlaku berem drugače, da sem bolj pozoren na vzdušje tega, kar berem« (M7).

»Na vlaku sem prebral vso klasiko in še zdaj imam to idejo, da se tam bere res dobra literatura« (M9).

8 Vreme je tudi sicer dejavnik, ki - kot so zatrdili številni intervjuvanci te in drugih raziskav - pogosto vpliva na bralno razpoloženje (gl. Burke, 2011; Kuzmičová idr., 2017). 
Zdi se, da je to primer okolja, ki deluje izrazito branju spodbudno, kar potrjuje še ena ugotovitev A. Kuzmičove (2016): to, da beremo, še ne pomeni, da ne zaznavamo neposrednega fizičnega okolja oziroma dogajanja v njem; to, da ga zaznavamo, pa nujno še ne pomeni, da nas moti. Nasprotno, okolje nam lahko zbuja ugodje ali (zaradi posebne atmosfere, korelacij med realnim in fiktivnim prostorom itd.) nas celo spodbudi k intenzivnemu doživljanju čtiva. Tozadevno koristi diferenciacija med pozornostjo in zaznavo (Schwitzgebel, 2007): če nekaj zaznam, še ne pomeni, da sem na to tudi pozoren, zato me nujno ne zmoti - pa četudi gre za branje, ki velja za enega najkompleksnejših procesov človeškega uma ter zahteva visoko raven pozornosti in percepcije. To, da med branjem zaznam okolje, tudi ne predpostavlja, da moram branje prej prekiniti, saj lahko zaznava okolja okupira le obrobje bralčeve zavesti. Okolice se torej lahko zavedamo in jo občutimo, ne da bi jo zares percipirali, sploh ker je med branjem naš pogled fiksiran in fokusiran na besedilo. A tudi če je ne vidimo, vemo, da je, in že samo to, t. i. epistemično zavedanje, ima svoj vpliv.

Premislek A. Kuzmičove korigira prej omenjeno Gerrigovo prispodobo, ki sugerira, da vživetje v zgodbo predpostavlja bralčevo odvezanost od okolice. Gerrig govori o znanem občutku, ko nas knjiga potegne vase in okolje postane nepomembno. A dejansko mora okolje v osnovi »dopustiti « vstop v knjigo, tj. dovoliti, da se odvežemo od njega, zato v resnici ni nikoli nepomembno. Realni, fizični prostor je vseskozi $\mathrm{v}$ interakciji $\mathrm{z}$ bralcem in uokvirja okolje pripovedi oziroma bralčevo mentalno predstavo narativnega ambienta. To »srečanje kontekstov« pa je lahko bolj ali manj "posrečeno«. Ne gre namreč samo za to, da okolje vpliva na bralca in njegovo branje, pač pa velja tudi obratno: bralec lahko zaradi branja okolje dojema drugače, kot bolj ali manj prijetno, moteče ali spodbudno, podobno kot lahko glasba spremeni atmosfero neke lokacije.

Tudi morski ambient je zato lep primer prelivanja ugodja. Užitek nam ponuja že prostor kot tak, in ta užitek se prenaša na branje sámo, obenem pa velja prej omenjeno - da je lahko prijetno okolje zelo dobra podlaga in stimulacija za spopadanje s težko literaturo.

»Ob morju sem prebrala filozofa Berdjajeva. Vanj se moraš res poglobiti in jaz sem ga namenoma vzela prav tja, na Bale, da bi ga v miru preštudirala« (Žl $)$.

A ne glede na to, kje vse berejo, dom ostaja osrednji bralni prostor velike večine sodelujočih. Branje povezujejo z udobjem, varnostjo in toplino domače atmosfere, $\mathrm{z}$ nekakšnim blagostanjem. V drugem okolju lahko zato prav s knjigo napihnejo svoj mehurček zasebnosti in poustvarijo ta občutek, ki je očitno tudi telesen. 
"Zame je branje močno povezano $\mathrm{z}$ domom in domačnostjo. In $\mathrm{v}$ tem me zelo spominja na pletenje. Ima podoben učinek. Klopke volne lahko vzamem in jih nesem na avtobus in sem tam v svojem mehurčku, podobno kot s knjigo« (Ž10).

$\mathrm{V}$ tem smislu $\mathrm{z}$ branjem vzpostavimo cono zasebnosti in ublažimo tesnobo ali napetost nekega prostora. S knjigo vanj interveniramo, si ga prisvojimo.

\section{Prostor (za) knjige}

»Ko sem enkrat poskusila brati na Kindlu, sem padla v paniko, sploh nisem imela občutka, kje sem, kaj je bilo prej, kaj bo potem, prostorsko sem se čisto zmedla, nekaj res pomembnega mi je manjkalo« (̌̌10).

Čeprav so tisti sogovorniki, ki knjige berejo tudi na zaslonu in imajo izkušnjo z različnimi bralnimi napravami, Amazonov Kindle ocenili kot do sedaj najboljši približek tiskani knjigi - »Kindle popolnoma enačim s tradicionalno knjigo« (Ž13); »Kindla sploh ne štejem za ekran« (Ž12) -, je vse (vsaj malo) zmotilo dejstvo, da besedilo ponikne v napravi in da bralec izgubi »orientacijo «. ${ }^{9}$ Sploh je mogoče opaziti, da o primerjavi elektronske in tiskane knjige razmišljajo zelo prostorsko.

»Pri branju na Kindlu mi manjka fizična prezenca, to, da vem, koliko strani imam še do konca, kje sem, skratka, ta prisotnost teksta, vse od tega, kakšna je bila videti knjiga, kakšne oblike je bila, kako sem jo držal ...« (M9).

Ti občutki niso neosnovani. Danes že vemo, da si bralci v zgodbi, ki jo preberejo z zaslona, slabše zapomnijo zaporedje dogodkov - torej kdaj oziroma kje v knjigi se kaj zgodi - kot tisti, ki isto zgodbo preberejo v tiskani knjigi (Mangen idr., 2014; Mangen idr., 2019). Vse kaže, da je to povezano ravno s specifično taktilnostjo papirja oziroma obračanja strani v tridimenzionalni knjigi; to namreč omogoči drugačno haptično izkušnjo, ki se močno razlikuje od rokovanja z zaslonsko napravo. ${ }^{10}$ Nasploh je očitno, da intervjuvanci fizični prisotnosti knjig pripisujejo velik pomen.

»Ker ne uporabljam kazalke, puščam knjige odprte. Všeč mi je, da je knjiga, ki jo bereš in nekje odložiš, odprto prisotna v prostoru, in ko hodiš po stanovanju, je tista knjiga del trenutnega dogajanja, če so vse knjige naložene na eni napravi, pa ne ...« $(\check{Z} 17)$.

9 Od vseh 17 sogovornikov jih vsaj občasno na zaslonu bere 8 , od tega 4 tudi za prosti čas. Ti štirje berejo tako na računalniku oziroma laptopu kot tudi na tablici, pametnem telefonu in Kindlu, ki ga izrazito favorizirajo.

10 Več o tem gl. Mangen, 2008 in Hillesund, 2010. Haptična razlika med e- in t-knjigo je del širše razprave o kvaliteti branja z zaslona v primerjavi z branjem s papirja. Danes lahko na osnovi številnih raziskav že zanesljivo trdimo, da tiskana besedila beremo bolj poglobljeno in si jih tudi bolje zapomnimo - gl. Baron, 2015; Singer idr., 2017; Delgado idr., 2018. 
Nekaj jih je povedalo, da knjigo, ki jo trenutno berejo, nosijo s sabo po hiši, kot da bi želeli ostati v stiku z vsebino, pa čeprav v resnici vedno berejo samo na eni lokaciji.

»Knjigo si prinesem tudi v banjo, ampak potem me začne skrbeti, da jo bom zmočila ..., tako da - knjiga je zraven, ampak je ne berem ...«(Ž10).

»Knjigo redno vlačim za sabo, potem pa jo kje odložim ... Tudi na stranišče jo vzamem, kot da bom bral, čeprav potem nikoli ne« (M7).

Za številne je pomembno, da imajo doma police s knjigami, ki branje vpišejo v prostor, in večina ima tudi sistem razporejanja naslovov, ki praviloma loči osebno pomembne knjige od ostalih; nekaj del obvezno hranijo na nočni omarici.

$»$ Knjige imam urejene po abecednem vrstnem redu in po žanrih, posebej imam fantasy in zbirke - Kondor, Sto romanov, Moderni klasiki in Beletrinine - to je tudi videti lepo. Ločeno imam postavljene tudi tiste knjige, ki sem jih jaz uredil ali jim napisal spremno besedo. Brez fizične prezence knjige ne bi mogel živeti; pomembno mi je tudi, da ljudje vidijo, kaj mi je všeč« (M9).

Posebej nazorno pomen prostorske bližine (izbranih) knjig ubesedi tale odgovor:

»Ko sva si z možem na novo uredila spalnico, sem knjige namenoma izbrala tako, da imam zdaj tam samo tiste, ki so nama ljube: mož ima svoje o hribih, jaz pa svoje študijske in za osebno rast. In zdaj lepo gledam te njihove hrbte v spalnici. To so knjige, ki sem jih nekako hotela zaščititi pred obiskovalci in jih tudi nočem posojati, nočem niti tega, da jih odpirajo in gledajo, medtem ko pa druge rada dajem naokrog« (Ž10).

Sogovorniki so veliko povedali tudi o svoji dovzetnosti za vizualno podobo knjige: številni jo dojemajo kot estetski objekt, ki lahko olepša prostor. Izbrani citati vsi po vrsti pričajo o tem, kako imajo knjige tudi prostorsko funkcijo.

\section{Branje kot kompleksna senzorična in (zato tudi) prostorska izkušnja}

Eno od vprašanj, ki sem jih postavila, se je nanašalo na spomin na močno bralno doživetje. Sogovornike sem prosila, naj opišejo kakšno svojo res prijetno bralno izkušnjo. Odzivi so nazorno pokazali, kako zelo branje v resnici občutimo in da je prostor pomemben del tega občutenja.

»Pri dobri knjigi dobim poseben telesen občutek, in ko pomislim nanjo, se ta občutek vrne ... Meni se leposlovje dogaja $\mathrm{v}$ trebuhu, to je prostor, kamor prihaja beseda; pri študiju pa se vse dogaja v glavi« (Ž10). 
Podobnih komentarjev je bilo veliko: »V telesu nosim občutek knjige« (Ž11); "Zelo čutim z junaki, včasih me prav boli, kdaj me kak slog ne pusti dihati in je branje fizično naporno« $(\check{Z} 2)$.

Največ (13 od 17) se jih je ob tem razgovorilo o branju v otroštvu ali mladosti. Zdi se, da so se jim posamezni naslovi vtisnili v spomin tudi zato, ker so jih kot otroci prebirali vedno znova, tudi po več desetkrat, česar kasneje običajno ne počnemo več, ali pa ker so takrat prvič doživeli moč knjige.

"Živo imam pred očmi prizor, ko sem za mizo pri kosilu brala Čarobno goro. Jedli smo fižolovo juho in brala sem poglavje, ko je Joachim umiral. To me je tako razžalostilo, da sem začela jokati in so mi solze kapljale v krožnik z juho ...«(Ž6).

A veliko jih je podelilo tudi intenzivno odraslo bralno doživetje.

»Ko sem bil pred časom na Tajvanu, sem v vročem in vlažnem vremenu bral Proustovo Iskanje izgubljenega časa, in to del, ki se dogaja pozimi. In tam, med Azijci, $\mathrm{v}$ čisto drugem vremenu, sem bil jaz kot preseljen v neko drugo okolje in mi sploh ni bilo vroče ... Še zdaj se mi, ko pomislim na Prousta, vedno stopita realna in fikcijska situacija tega branja ... [...] To velja tudi za nekatera druga branja; za posamezne scene v knjigah, ki so se me dotaknile, točno vem, kje sem jih bral« (M9).

Opisano simultano doživljanje realnega in imaginarnega okolja je lep primer tega, kar bi lahko opisali z izrazom »tretji prostor «. ${ }^{11}$ »Tekst me včasih tako zagrabi, da rabim kar nekaj časa, da pridem ven, (M9) o svoji ujetosti v ta vmesni prostor pravi isti bralec.

Fizično-prostorsko je tudi tole bralno »razsvetljenje«, in ni naključje, da se zgodi ob morju:

"Spomnim se knjige Tineta Hribarja, naslov sem pozabila, bila je taka manjša, bela. Brala sem jo na morju, v Premanturi, bilo je že zdavnaj, in prav spomnim se, kako sem tam lahko vse razumela, kako sem se zbrala, vreme je bilo krasno, veter je pihljal, mir so mi dali, in to je bilo tako zadoščenje, tako slastno branje, prekrasna izkušnja. Zdelo se mi je, da prav fizično boljše vidim« (Ž5).

Navedeni opisi so primer t. i. epizodnega spomina, tj. spomina na specifične situacije in dogodke, ki ob tem, kaj, kdo, kje in kdaj, celostno vključuje tudi občutke in čustva, povezana s tem konkretnim doživljajem (Eysenck idr., 1990, 250). Kot tak

11 Tretji prostor je zelo fleksibilen koncept, odprt za interpretacijo. Različne discipline ga zato aplicirajo različno, $v$ vsakem primeru pa gre za idejo vmesnosti in preseganja pripadnosti eni od dveh možnosti oziroma entitet. Za naše razumevanje je do določene mere uporabna Oldenburgova definicija, ki tretji prostor razume kot cono med javnim in zasebnim (1989). Gl. tudi H. K. Bhabha (1994) in Soja (1996). 
je izrazito kontekstualiziran in izkustven ter blizu t. i. avtobiografskemu spominu, kjer gre za spominjanje naših lastnih dogodkov, v katerih emocije igrajo ključno vlogo. Spomini na čustveno intenzivna branja tako razumljivo vključujejo tudi konkreten prostor oziroma lokacijo. V tem smislu bralni doživljaji različnih intenzivnosti nizajo celo vrsto čustvenih spominov. "Zapomniti si knjigo iz svojega otroštva pomeni zapomniti si otroka, kako je bral to knjigo, « v študiji lastnega branja zapiše Margaret Mackey $(2016,5) .{ }^{12}$

Ko sem sogovornike prosila, da opišejo idealne bralne okoliščine, so se pogosto navezali prav na lastne spomine ali pa so opisali svoje običajno branje s to ključno razliko, da bi imeli več časa.

»Moj najljubši kotiček za branje je na barki, ko smo zasidrani in pljuska morje, ko dvigneš pogled, pa vidiš morje in slišiš galebe. Dvajset let sem hodila na take počitnice, zdaj pa žal ne več« (Ž2).

»Najboljše mi je, če od nekod pridem in sem fizično utrujena, potem pa berem. Idealno bi bilo, če bi zvečer res lahko imela eno do dve uri za branje pred spanjem« (Ž12).

Nekaj jih je sicer imelo izdelano predstavo o popolnem bralnem prizoru, a so priznali, da imajo v sebi te podobe iz medijev, v resnici pa jih nikoli ne prakticirajo, niti si zanje posebej ne prizadevajo. Pogosto se tudi zgodi, da dejanska izkušnja ne izpolni pričakovanj.

»Pravzaprav se nikoli ne potrudim dovolj, da bi si pri branju ustvaril idealne okoliščine« (M7).

»Ko postavimo božično smrekico, se mi vedno zdi, da moram zraven nje brati, ker je to lep prizor. Ampak v bistvu ni nič posebnega, tako kot tudi ni nič posebnega, če bereš na tropskem otoku - vem, ker sem že poskusila« (Ž13).

\section{Zaključna refleksija}

Odgovori 17 sogovornikov lahko ponudijo zgolj omejen uvid v prostorskost branja, kljub temu pa dovolj prepričljivo pokažejo, da prostor pomembno soustvari bralno izkušnjo in predvsem fizični občutek pri branju. Prav o telesnosti branja so imeli moji sogovorniki (delež sodelujočih moških je bil premajhen, da bi lahko na tej osnovi sklepali o morebitnih razlikah med moškim in ženskim branjem) veliko povedati.

12 V tem smislu je zanimivo raziskovanje učinkov ponovnega branja - več o tem v On Rereading $\mathrm{P}$. Meyer Spacks (2011). 
Intervjuvanci so jasno artikulirali tipe branja, lokacije in pripadajoče protokole ter praviloma tudi reflektirano utemeljevali, zakaj berejo tako, kot berejo. Več kot so brali, natančneje so bile določene njihove preference. Marsikatere navade se zdijo pričakovane in ni težko pokazati na skupne imenovalce, vendar se ti pokažejo $\mathrm{v}$ različnih niansah in sestavljajo povsem individualne profile bralcev.

$\mathrm{V}$ odgovorih sogovornikov dom zaseda osrednji bralni prostor, zato branje običajno povezujejo z zasebnostjo, mirom in sprostitvijo, kar pa lahko prav z branjem vsaj do določene mere poustvarijo tudi zunaj doma. Izrazito izstopata pogostost in samoprepoznavanje telesnih občutkov ob branju, neredko v navezavi na neposredno fizično okolje, in percepcija knjige kot prostorskega objekta.

Pogovori so torej potrdili, da prostor branju vtisne svoj pečat in (p)ostane del bralnega doživetja, tudi ko nas knjiga povsem prevzame. Kot zapiše McLaughlin: »Odmik od okolja je še vedno način bivanja v tem okolju« $(2015,97)$.

Analizo prostora branja bi lahko nadgradili na različne načine. Prvič, po zgledu Jennifer Nolan-Stinson $(2008,2011)$ bi jo lahko poglobili z vključitvijo konkretnih bralnih lokacij, tako da bi intervjuje izvedli in situ, na domu bralcev, in gradivo strukturirali v nekakšne bralske profile, ki bi ob fizični upoštevali tudi družbenokulturno dimenzijo okolja.

Drugič, osredotočili bi se lahko na primere branj konkretnih del, saj so prav ti prispevali najbolj doživete in natančne opise, zato bi bilo smiselno večkrat prositi za podelitev takšnih osebnih spominov.

Tretjič, ker je bilo med mojimi sogovorniki malo tistih, ki bi digitalno brali kaj več kot le novice ali sicer nedostopno študijsko gradivo, ostaja ta tip branja v okviru moje raziskave slabše raziskan. Ob pragmatičnem rekrutiranju intervjuvancev bi lahko v nadaljevanju bolje preučili tudi prostorsko umeščenost e-branja. To je še posebej zanimivo zato, ker sodobne bralne naprave omogočajo veliko izbiro čtiva, kar pomeni, da lahko glede na trenutni navdih in situacijo poiščemo kar najustreznejše branje. Kindle in drugi bralniki olajšujejo takšno eksperimentiranje oziroma kombiniranje. Kot smo že ugotovili: »Odnos med bralnim telesom in prostorom, ki ga naseljuje, je dialektičen: prostor zaznamuje branje in branje zaznamuje prostor « (McLaughlin, 2015, 139). Prav zato bi veljalo, in to je še ena možna smer nadaljnjega raziskovanja, $\mathrm{v}$ kateri od prihodnjih študij spremljati branje iste knjige v različnih okoliščinah, in obratno, branje različnih del v enakih okoliščinah, po možnosti zunaj doma, ker smo doma po navadi tako ali tako vajeni brati vse.

A vseskozi se zdi ključen kvalitativni pristop, analiza posameznikovih bralnih praks s pomočjo bralčeve lastne refleksije. Kot v uvodu k svoji »avtobibliografiji« 
ugotavlja Margaret Mackey (2016) in kot je vedel vsaj že Joyce, se »v partikularnem skriva univerzalno«, zato prav vpogled v individualna branja pomembno pripomore $\mathrm{k}$ boljšemu razumevanju naših bralnih doživetij.

\section{Bibliografija}

Baron, S. N., Words Onscreen. The Fate of Reading in a Digital Age, New York 2015.

Bhabha, H. K., The Location of Culture, London 1994.

Burgess, S. R. idr., Relations of the home literacy environment (HLE) to the development of reading-related abilities: a one-year longitudinal study, Reading Research Quarterly, 32.4, 2002, str. 408-426.

Burke, M., Literary Reading, Cognition and Emotion: An Exploration of the Oceanic Mind, New York 2011.

Chartier, R., Red knjig. Bralci, avtorji in knjižnice v Evropi med 14. in 18. stoletjem, Ljubljana 2011.

Colclough, S., Consuming Texts: Readers and Reading Communities, 1695-1870, Basingstoke 2007.

Colclough, S., Representing Reading Spaces, v: The History of Reading: Methods, Strategies, Tactics (ur. Crone, R. idr.), Basingstoke 2011, str. 99-114.

Delgado, P. idr., Don't throw away your printed books: A meta-analysis on the effects of reading media on reading comprehension, Educational Research Review, 25, 2018, str. 23-38.

Dović, M., Sistemske in empirične obravnave literature, Ljubljana 2004.

Eysenck, M. W. idr., Cognitive Psychology: A Student's Handbook, Mahwah 1990.

Fischer, S. R., A History of Reading, London 2004.

Flint, K., The Woman Reader 1837-1914, Oxford 1993.

Gerrig, R. J., Experiencing Narrative Worlds. On the Psychological Activities of Reading, New Haven 1993.

Green, M. C. idr., The role of transportation in the persuasiveness of public narratives, Journal of Personality and Social Psychology 79 (5), 2000, str. 701-721.

Hillesund, T., Digital reading spaces. How expert readers handle books, the Web and electronic paper, First Monday 15 (4), 2010.

Kamarulzaman, N. idr., An Overview of the Influence of Physical Office Environments Towards Employees, Procedia Engineering, 20, 2011, str. 262-268.

Kovač, M. idr., Knjiga in bralec V. Bralna kultura in nakupovanje knjig $v$ Sloveniji, Ljubljana 2015. 
Kuzmičová, A. idr., Reading and Company: Embodiment and Social Space in Silent Reading Practices, Literacy, 52 (2), 2017, str. 70-77.

Kuzmičová, A., Does it Matter Where You Read? Situating narrative in physical environment, Communication Theory 26.3, 2016, str. 290-308.

Leseman, P. P. M. idr., Home literacy: opportunity, instruction, cooperation and social-emotional quality predicting early reading achievement, Reader Research Quarterly 33.3, 1998, str. 294-318.

Littau, K., Theories of Reading. Books, Bodies and Bibliomania, Cambridge 2006.

Mackey, M., One Child Reading. My Auto-Bibliography, Edmonton 2016.

Mangen, A. idr., Comparing Comprehension of a Long Text Read in Print Book and on Kindle: Where in the Text and Where in the Story?, Frontiers in Psychology 10, 2019, https://www.frontiersin.org/article/10.3389/fpsyg.2019.00038, [27. 11. 2019].

Mangen, A. idr., Lost in an iPad: Narrative engagement on paper and tablet, Scientific Study of Literature 4.2, 2014, str. 150-177.

Mangen, A., Hypertext Fiction Reading: Haptics and Immersion, Journal of Research in Reading 31 (4), 2008, str. 404-419.

Manguel, A., The History of Reading, Oxford 1997.

McLaughlin, T., Reading and the Body: The Physical Practice of Reading, Basingstoke 2015.

Meyer Spacks, P., On Rereading, Cambridge 2011.

Nolan-Stinson, J., Reading Beyond the Page: Contextualizing Reading Within the Lives of Avid Readers, College Park 2008.

Nolan-Stinson, J., Toward a Life History of Reading, Reception: Texts, Readers, Audiences, History, 3 (3), 2011, str. 35-58.

Oldenburg, R., The Great Good Place. Cafes, Coffee Shops, Community Centers, General Stores, Bars, Hangouts, and How They Get You through the Day, New York 1989.

Raven, J. idr., The Practice and Representation of Reading in England, Cambridge 1996.

Rowlands, M., The new science of the mind: From extended mind to embodied phenomenology, Cambridge 2010.

Sadoski, M., Reading Comprehension is Embodied. Theoretical and Practical Considerations, Educational Psychology Review, 30 (2), 2018, str. 331-349.

Schwitzgebel, F., Do you have constant tactile experience of your feet in your shoes? Or is experience limited to what's in attention? Journal of Consciousness Studies 14 (3), 2007, str. 5-35. 
Singer, L. idr., Reading on paper and digitally: What the past decades of empirical research reveal, Review of Educational Research, 87 (6) 2017, str. 1007-1041.

Soja, E. W., Thirdspace: Journeys to Los Angeles and Other Real-and-Imagined Places, Oxford 1996.

Vischer, J. C., Towards an Environmental Psychology of Workspace: How People are affected by Environments for Work, Architectural Science Review, 51.2, str. 97-108.

Williams, A., The Social Life of Books. Reading Together in the Eighteenth-Century Home, New Haven 2017.

Wilson, M., Six views of embodied cognition. Psychonomic bulletin \& review 9 (4), 2002, str. 625-636. 
Ana Vogrinčič Čepič

\section{Branje kot prostorska praksa: odnos bralcev do neposrednega fizičnega prostora branja}

Ključne besede: bralno doživetje, bralno okolje, telesnost branja, poglobljeni intervju

Čeprav se branje kot dejavnost vselej nujno vpisuje v konkreten čas in prostor, so se študije branja do nedavnega osredotočale predvsem na njegovo mentalno dimenzijo, tj. na interpretacijo prebranega, z neposrednim fizičnim okoljem branja pa se - razen v zgodovinski analizi oziroma pedagoško-didaktični obravnavi kontekstov opismenjevanja - niso kaj dosti ukvarjale.

Pričujoči članek skuša na podlagi poglobljenih individualnih pogovorov z bralci o njihovih bralnih navadah izluščiti, kako realni prostor branja sooblikuje bralno izkušnjo. Osredotoča se na branje leposlovja za prosti čas in na branje domá, ki so ga sogovorniki postavili v središče, obravnava branje na prostem in v javnosti, dotika pa se tudi vprašanja, kako prostor branja spreminja digitalizacija. Pri tem vseskozi izhaja iz branja kot izrazito telesne in materialne prakse.

Kot se izkaže, bralci niso indiferentni do svojih neposrednih bralnih okolij in se večinoma zavestno odločajo, kaj bodo kje brali. Očitno je tudi, da branje dojemajo kot izrazito senzorično izkušnjo. K razumevanju naslovne tematike pomembno prispevajo bralčevi spomini na močna bralna doživetja, ki praviloma vselej vključujejo oprijemljivo prostorsko konkretnost.

Članek sklepa premislek o nadaljnjih pristopih $\mathrm{k}$ raziskovanju prostorske materialnosti branja. 


\section{Ana Vogrinčič Čepič}

\section{Reading as a Spatial Practice: Readers and Their Physical Reading Environments}

Keywords: reading experience, reading environment, in-depth interview, the embodiment of reading

Despite the fact that the process of reading is always inscribed in time and place, studies of reading have traditionally focused on its mental dimension, i.e. on the interpretation of what has been read, and (with the exception of historical analysis and research on literacy) haven't dealt much with the direct physical reading environment.

Based on individual in-depth interviews with readers about their reading habits, this article tries to pinpoint how the actual place of reading shapes the reading experience. It focuses on reading fiction for leisure and on reading at home, because this is what the participants themselves paid most attention to, but also deals with reading outdoors and in public, and touches upon the way the reading environment is changed by the process of digitisation. Throughout, the emphasis is on reading as an embodied and material practice.

As it turns out, readers are not indifferent towards their immediate reading environments, and they usually consciously manage what and where will they read. It is very clear that they regard reading as a deeply sensorial experience. What importantly contributes to a better understanding of the topic are readers' memoires of their own readings, since they are often remembered together with vivid spatial detail.

The conclusion reflects on prospects for future research on the environmental dimensions of reading, mainly with the use of personal memoirs. 